Published in final edited form as:

Obstet Gynecol. 2018 October ; 132(4): 868-874. doi:10.1097/AOG.0000000000002874.

\title{
Delivery-to-Delivery Weight Gain and Risk of Hypertensive Disorders in a Subsequent Pregnancy
}

\author{
Annie M. DUDE, MD, PhD ${ }^{\mathrm{a}}$, Sarrah SHAHAWY, MD ${ }^{\mathrm{b}}$, and William A. GROBMAN, MD, MBA ${ }^{\mathrm{a}}$ \\ aDivision of Maternal-Fetal Medicine, Department of Obstetrics \& Gynecology, Feinberg School of \\ Medicine, Northwestern University \\ ${ }^{b}$ Department of Obstetrics \& Gynecology, Feinberg School of Medicine, Northwestern University
}

\begin{abstract}
Objective: To estimate whether weight gain between deliveries is associated with an increased risk of hypertensive disorders in a subsequent pregnancy.

Methods: This is a case-control study of women who had two live singleton births of at least 24 weeks of gestation at a single maternity hospital from January 1, 2005 to December 31, 2015, with no hypertensive disorder documented in the index pregnancy. Maternal weight gain between deliveries was measured as the change in body mass index (BMI) at delivery. Women who were diagnosed with any hypertensive disorder in the subsequent pregnancy were compared with those who experienced no hypertensive disorder in the subsequent pregnancy using chi square statistics for categorical variables and $t$ tests for continuous variables. Logistic regression was used to determine whether weight gain remained independently associated with hypertensive disorders after adjusting for potential confounders.
\end{abstract}

Results: Of 1,033 women, $188(18.2 \%)$ were diagnosed with a hypertensive disorder in the subsequent pregnancy. Of these, $166(88.3 \%)$ had a hypertensive disorder specific to pregnancy (gestational hypertension, preeclampsia, superimposed preeclampsia, or hemolysis, elevated liver enzymes, and low platelet count syndrome) whereas 22 (11.7\%) had chronic hypertension only. Greater weight gain between deliveries was significantly associated with a higher frequency of hypertensive disorders, which remained significant for a BMI increase of at least $2 \mathrm{~kg} / \mathrm{m}^{2}$ in multivariable analyses (adjusted odds ratio $[\mathrm{OR}]=1.76,95 \% \mathrm{CI}=1.14-2.74$ for 2 to $<4 \mathrm{~kg} / \mathrm{m}^{2}$, adjusted $\mathrm{OR}=3.19,95 \% \mathrm{CI}=1.86-5.47$ for $4 \mathrm{~kg} / \mathrm{m}^{2}$ or more). Conversely, weight loss of $2 \mathrm{~kg} / \mathrm{m}^{2}$ or more was associated with a decreased risk of a hypertensive disorder (adjusted OR $=0.41,95 \%$ $\mathrm{CI}=0.21-0.81)$.

CORRESPONDING AUTHOR: Annie Dude, 250 East Superior Street, Suite 5-2185, Chicago, IL 60611; annie.dude@ gmail.com; Tel: (312) 472-4649 Fax: (312) 472-4687.

Financial Disclosure

The authors did not report any potential conflicts of interest.

Each author has indicated that he or she has met the journal's requirements for authorship.

Precis: Among women with no hypertension in an index pregnancy, increased delivery to delivery weight gain was associated with an increased risk of hypertensive disorders in a subsequent pregnancy. 
Conclusion: Among women with no hypertensive disorder noted in an index pregnancy, an increase in BMI of at least $2 \mathrm{~kg} / \mathrm{m}^{2}$ between deliveries was independently associated with an increased risk of a hypertensive disorder in a subsequent pregnancy.

\section{Introduction:}

Hypertensive disorders of pregnancy affect approximately 5-9\% of all pregnancies in the United States, ${ }^{1}$ with the prevalence increasing recently. ${ }^{2}$ They are a common cause of maternal mortality, ${ }^{3}$ medically-indicated preterm delivery, ${ }^{4}$ and stillbirth. ${ }^{5}$ Hypertensive disorders in pregnancy are also associated with poor long-term cardiovascular health. 6,7

Approximately two-thirds of U.S. adults are overweight or obese (body mass index [BMI] $\geq$ $\left.25 \mathrm{~kg} / \mathrm{m}^{2}\right) .{ }^{8}$ The association of excess pre-pregnancy body weight with adverse pregnancy outcomes, including hypertensive disorders, has been demonstrated. ${ }^{9}$ Excessive gestational weight gain (weight gain that exceeds Institute of Medicine recommendations) also has been associated with higher odds of hypertensive disorders. ${ }^{10}$

Yet, whether a change in weight between deliveries (i.e., delivery to delivery weight gain) is associated with hypertensive disorders following an index pregnancy in which a woman did not develop a hypertensive disorder is unclear. Pre eclampsia, in particular, is often thought of as a disorder more common in first pregnancies. ${ }^{11}$ A population-based study from Utah showed that the odds of pre eclampsia in a subsequent pregnancy significantly increased with increasing BMI, but the overall effect was small. ${ }^{12}$ Another clinical study from Australia showed no association between weight gain between pregnancies and hypertensive disorders. ${ }^{13}$

The purpose of this study was to determine whether delivery to delivery weight gain is associated with the odds of developing any hypertensive disorder by the time of a subsequent delivery in women with no hypertension in an index pregnancy.

\section{Methods:}

This is an unmatched case-control study of women at least 18 years of age who delivered two consecutive live singleton births of at least 24 weeks' gestation at Northwestern Memorial Hospital in Chicago, IL between January 2005 and December 2015. Women were identified through a query of the hospital's electronic data warehouse, in which all medical record data from a variety of electronic record sources (e.g., inpatient and outpatient records, billing, and pharmacy) are compiled. Women were included if they had no diagnosis of a hypertensive disorder in the index pregnancy and a subsequent delivery at the same institution. 'Cases' were defined as women who experienced a hypertensive disorder in the subsequent pregnancy, and 'controls' were defined as women who did not experience a hypertensive disorder. Approval for this study was obtained from the Northwestern Biomedical Sciences Institutional Review Board with a waiver of informed consent.

Demographic, maternal, and obstetric data, including whether a woman was diagnosed with a hypertensive disorder in the subsequent pregnancy and type of hypertensive disorder, if applicable, were abstracted from the electronic medical record. A woman was classified as 
having a hypertensive disorder only if she met the formal criteria for a hypertensive disorder, as defined by the American College of Obstetricians and Gynecologists' Task Force on Hypertension in Pregnancy. ${ }^{14}$ Thus, for instance, a patient that had a single isolated systolic blood pressure $>140 \mathrm{mmHg}$ but no further elevated pressures would not have been categorized as having gestational hypertension.

Weight change was defined as the difference in BMI at the time of the subsequent delivery from BMI at the time of the index delivery. We chose a priori to use weight at delivery as opposed to preconception, or at time of entrance to prenatal care, as women in this study entered prenatal care at all trimesters of pregnancy. Furthermore, outpatient records were not available for all patients. Delivery weight was obtained by weighing patients upon admission. In order to assist with clinical translation of the results, BMI change was categorized as loss of $2 \mathrm{~kg} / \mathrm{m}^{2}$ or greater, loss of $2 \mathrm{~kg} / \mathrm{m}^{2}$ or less to gain of $2 \mathrm{~kg} / \mathrm{m}^{2}$, gain more than $2 \mathrm{~kg} / \mathrm{m}^{2}$ and less than $4 \mathrm{~kg} / \mathrm{m}^{2}$, and gain of $4 \mathrm{~kg} / \mathrm{m}^{2}$ or more. This classification scheme was adapted from Jain et. al., who chose a BMI gain or loss of $2 \mathrm{~kg} / \mathrm{m}^{2}$ as a clinically meaningful amount of change (about 12 pounds for a 5 foot 4 inch woman). ${ }^{15}$

Other variables included in multivariable models were: BMI at the index delivery, maternal age in years at the index delivery, any diabetes (pre-existing or gestational) in the subsequent pregnancy, parity (defined as one or two or more previous deliveries of at least 20 weeks' gestational age at the time of the subsequent delivery), and the time (years) elapsed between deliveries. Race and ethnicity were defined as white non-Hispanic, black non-Hispanic, Hispanic, Asian, or other. Variables were retained in multivariable models if they were significantly different between groups at the $\mathrm{p} \leq 0.10$ level in bivariable comparisons with either weight change or with a hypertensive disorder.

Bivariable comparisons were performed using the student $t$ test or one-way ANOVA for continuous variables and chi square tests for categorical variables. Multivariable logistic regression was used to adjust for potential confounders. Analyses were performed comparing BMI change to the likelihood of any hypertensive disorder, as well as the likelihood of a hypertensive disorder specific to pregnancy (gestational hypertension, pre eclampsia, superimposed pre eclampsia, or hemolysis, elevated liver enzymes, and low platelet count [HELLP] syndrome). In order to account for possible selection bias across weight change groups, we also ran all models using propensity-based weighting and stratification, using an ordered logit link function and 10 strata in each treatment category. Given that our 'treatment' variable has more than two groups, we chose the marginal mean weighting through stratification method, ${ }^{16}$ which is used to reweight a dataset to balance observed characteristics across all treatment groups. We used the same variables to generate these weighted observations as we used in the logistic regression models. All hypothesis tests were two-tailed, and a probability value of 0.05 was used to determine statistical significance. All analyses were carried out in STATA (version 14.1, StataCorp, College Station, TX). 


\section{Results:}

Of the 1,138 women that otherwise met eligibility criteria, 105 women had missing information on race and ethnicity and were excluded from the study population. Women did not differ in their likelihood of developing any hypertensive disorder $(\mathrm{p}=0.83)$, a hypertensive disorder specific to pregnancy $(p=0.88)$ or in weight change $(p=0.79)$ based on whether they were missing information on race and ethnicity. Data were complete for all other variables, including weight change and other potential confounding factors.

Of the 1,033 women remaining in the study pcohort, $18.2 \%$ ( $\mathrm{n}=188)$ developed any hypertensive disorder by the time of the subsequent delivery. Of these 188 women, $29.8 \%$ $(\mathrm{n}=56)$ were diagnosed with gestational hypertension, $50.0 \%(\mathrm{n}=94)$ with pre-eclampsia, $3.7 \%(\mathrm{n}=7)$ with superimposed pre-eclampsia, and 4.8\% ( $\mathrm{n}=9$ ) developed HELLP syndrome. Of the 188 women, $11.7 \%(\mathrm{n}=22)$ were diagnosed with chronic hypertension either prior to conceiving the subsequent pregnancy, or prior to 20 weeks' gestation. The average BMI at delivery in the index pregnancy was $30.7 \mathrm{~kg} / \mathrm{m}^{2}$ (standard deviation $[\mathrm{SD}]=5.9$ ) and in the subsequent pregnancy was $31.2 \mathrm{~kg} / \mathrm{m}^{2}(\mathrm{SD}=6.4)$. In this population, $12.8 \%(\mathrm{n}=132)$ lost more than $2 \mathrm{~kg} / \mathrm{m}^{2}$ between deliveries, $14.4 \%(\mathrm{n}=149)$ gained from 2 to $<4 \mathrm{~kg} / \mathrm{m}^{2}$, and $7.7 \%$ $(\mathrm{n}=80)$ gained 4 or more $\mathrm{kg} / \mathrm{m}^{2}$. The remainder $(65.1 \%, \mathrm{n}=672)$ neither gained nor lost more than $2 \mathrm{~kg} / \mathrm{m}^{2}$ between deliveries.

Weight gain of $2 \mathrm{~kg} / \mathrm{m}^{2}$ or more between deliveries was associated with an increased risk of any hypertensive disorder in bivariable analysis $(\mathrm{p}<0.001$; Table 1$)$. This finding persisted in multivariable analysis: gains of 2 to $<4 \mathrm{~kg} / \mathrm{m}^{2}$ (adjusted odds ratio $[\mathrm{OR}]=1.76,95 \% \mathrm{CI}=$ $1.14-2.74$ ) and $4 \mathrm{~kg} / \mathrm{m}^{2}$ or more (adjusted $\mathrm{OR}=3.19,95 \% \mathrm{CI}=1.86-5.47$ ) were associated with an increased risk of any hypertensive disorder (Table 1). Conversly, weight loss was associated with a decreased risk of any hypertensive disorder (adjusted $\mathrm{OR}=0.41,95 \% \mathrm{CI}=$ $0.21-0.81$ ). Time between deliveries was also associated with an increased risk of any hypertensive disorder (adjusted $\mathrm{OR}=1.27,95 \% \mathrm{CI}=1.13-1.44$ ), as was $\mathrm{BMI}$ in the index pregnancy, with the odds of a hypertensive disorder increasing by 1.05 for every $\mathrm{kg} / \mathrm{m}^{2}(95 \%$ $\mathrm{CI}=1.02-1.09)$.

When examining the specific type of hypertensive disorder, gain of $2 \mathrm{~kg} / \mathrm{m}^{2}$ or greater was associated with an increased risk of a hypertensive disorder specific to pregnancy in both bivariable $(\mathrm{p}<0.001)$ and multivariable models (adjusted $\mathrm{OR}=1.82,95 \%$ CI $1.16-2.86$ for a weight increase of 2 to $<4 \mathrm{~kg} / \mathrm{m}^{2}$; adjusted $\mathrm{OR}=2.72 ; 95 \% \mathrm{CI}=1.52-4.87$ for a weight increase of $4 \mathrm{~kg} / \mathrm{m}^{2}$ or more). Similarly, loss of $2 \mathrm{~kg} / \mathrm{m}^{2}$ or greater was associated with a decreased risk of a hypertensive disorder specific to pregnancy (adjusted $\mathrm{OR}=0.46,95 \% \mathrm{CI}$ $=0.23-0.90)$. (Table 2$)$.

We examined factors associated with BMI change between deliveries. BMI change between deliveries was significantly associated with BMI at the time of initial delivery, race, ethnicity, maternal age, parity, time between pregnancies, and diabetes in the subsequent delivery (Table 3).

As a sensitivity analysis, given that a woman's past history of a hypertensive disorder is so predictive of future hypertensive disorders, we repeated our analyses limiting our sample to 
women who have had only two pregnancies (the two observed in these data) to ensure women did not have a history of pre-eclampsia in a prior pregnancy. All associations between weight change and hypertensive disorders remained the same in terms of direction and magnitude, apart from a decreased risk of any hypertensive disorder associated with weight loss, which was no longer statistically significant (adjusted $\mathrm{OR}=0.47,95 \% \mathrm{CI}=$ $0.22-1.01)$. Similarly, our results regarding the association between weight change and any hypertensive disorder, as well as any de novo hypertensive disorder, did not substantively change when propensity-score based weighting and stratification were used for analysis (Table 4), with the exception that weight loss was only predictive of a decreased risk of any hypertensive disorder, rather than hypertensive disorders specific to pregnancy (adjusted OR $=0.54,95 \% \mathrm{CI}=0.28-1.07$, full results in Table $\mathrm{S} 1$ ).

\section{Discussion}

This main finding of the study is that weight gain between deliveries is associated with any hypertensive disorder in a subsequent pregnancy following a pregnancy unaffected by a hypertensive disorder. Weight loss between deliveries was associated with a decreased risk of hypertensive disorders. We have showed that weight gain is an independent risk factor for hypertensive disorders even when accounting for a woman's initial BMI. These findings are consistent with other studies that have largely used administrative, as opposed to clinical, data. ${ }^{17}$

In our study, weight gain between deliveries could be due to interpregnancy weight gain, postpartum weight retention, gestational weight gain in the subsequent pregnancy, or some combination of these factors. These findings underscore the importance of managing weight between deliveries, by promoting postpartum weight loss, controlling inter-pregnancy weight gain, or limiting gestational weight gain. As we are unable to distinguish between weight gained during these different time periods, however, further study is warranted to see whether weight change associated with all three are equally predictive of hypertensive disorders.

This study adds to the literature on the role of the delivery to delivery interval and the risk of hypertensive disorders. Previous literature indicates that a longer span of time between deliveries is associated with an increased risk of pre-eclampsia, even approaching that of first pregnancies as time elapsed, ${ }^{18-20}$ but it remained unclear whether this was due to increased maternal age, weight gain, or some other factor. This study indicates that increased time itself between deliveries increases the risk of hypertensive disorders independent of maternal age and weight gain. The increased risk of hypertensive disorders is also not due merely to the development of chronic hypertension over time. The delivery to delivery interval thus represents another potentially modifiable variable that may reduce the risk of hypertensive disorders. Strictly from the perspective of hypertensive disorders, a shorter interval between pregnancies may prove beneficial, although this risk should be weighed in consideration with the risks of shorter interpregnancy intervals such as possible increased risk of preterm delivery. ${ }^{21}$ 
This study has several limitations. Firstly, measuring change as BMI difference at the time of delivery does not allow us to distinguish between postpartum weight retention following the initial pregnancy, weight gain that occurred in the interval between pregnancies, or gestational weight gain in the subsequent pregnancy. Thus, we are unable to distinguish if any of these are more associated with hypertensive disorders than the others, which would allow for a more targeted intervention. Secondly, weight at delivery may be artificially elevated in women with a hypertensive disorder due to retained fluid secondary to the disease process; this is a confounder for which we cannot control. Other confounders for which we cannot control are increased weight due to excess amniotic fluid, or for smoking, the data for which were inconsistently collected for this cohort, as well as whether women took aspirin as a preventative measure. Thirdly, as this is an observational study, we cannot infer causality. There is a risk of residual confounding, as in any large, observational study, including residual confounding from other medical conditions also associated with hypertensive disorders of pregnancy, such as lupus. Fourthly, these data come from a single tertiary care institution and a single community hospital, and may lack external validity in other practice settings, especially in terms of the baseline risk profile for hypertensive disorders and prevalence of hypertensive disorders among this obstetric population. Fifthly, it is impossible to know with certainty whether women changed partners between pregnancies. Finally, it should be noted that while statistically significant, the absolute difference in risk of a hypertensive disorder based on weight change category is small.

The strengths of the study include a large, racially and ethnically diverse clinical sample. While Northwestern is a large academic medical center, it has large numbers of both lowrisk and high-risk patients, increasing the generalizability of these results to other settings. We were also able to obtain detailed information from the clinical record regarding maternal diabetes status, as well as the specific type of hypertensive disorder, which may not be available in administrative datasets.

We conclude that a weight gain of $\geq 2 \mathrm{~kg} / \mathrm{m}^{2}$ or more is associated with higher odds of being diagnosed with any hypertensive disorder in a subsequent pregnancy, as well as increased odds of developing a hypertensive disorder specific to pregnancy, whereas weight loss of 2 $\mathrm{kg} / \mathrm{m}^{2}$ or more was associated with lower odds of hypertensive disorders. This association is independent of maternal age, race, parity, diabetes, initial BMI, and time interval between deliveries.

\section{Supplementary Material}

Refer to Web version on PubMed Central for supplementary material.

\section{Acknowledgments}

FUNDING: Research reported in this publication was supported, in part, by the National Institutes of Health's National Center for Advancing Translational Sciences, Grant Number UL1TR001422. The content is solely the responsibility of the authors and does not necessarily represent the official views of the National Institutes of Health. 


\section{References:}

1. Centers for Disease Control and Prevention. Data on selected pregnancy complications in the United States: hypertensive disorders, 1993-2014. 2017.

2. Kuklina EV, Ayala C, Callaghan WM. Hypertensive disorders and severe obstetric morbidity in the United States. Obstet Gynecol. 2009;113(6):1299-1306. [PubMed: 19461426]

3. Creanga AA, Syverson C, Seed K, Callaghan WM. Pregnancy-related mortality in the United States, 2011-2013. Obstet Gynecol. 2017;130(2):366-373. [PubMed: 28697109]

4. Goldenberg RL, Culhane JF, Iams JD, Romero R. Epidemiology and causes of preterm birth. Lancet. 2008;371(9606):75-84. [PubMed: 18177778]

5. Hirst JE, Villar J, Victora CG, et al. The antepartum stillbirth syndrome: risk factors and pregnancy conditions identified from the INTERGROWTH-21(st) Project. BJOG. 2016.

6. Canoy D, Cairns BJ, Balkwill A, et al. Hypertension in pregnancy and risk of coronary heart disease and stroke: A prospective study in a large UK cohort. Int J Cardiol. 2016;222:1012-1018. [PubMed: 27529390]

7. Behrens I, Basit S, Lykke JA, et al. Association between hypertensive disorders of pregnancy and later risk of cardiomyopathy. JAMA. 2016;315(10):1026-1033. [PubMed: 26954411]

8. Flegal KM, Kruszon-Moran D, Carroll MD, Fryar CD, Ogden CL. Trends in obesity among adults in the United States, 2005 to 2014. JAMA. 2016;315(21):2284-2291. [PubMed: 27272580]

9. Bodnar LM, Ness RB, Markovic N, Roberts JM. The risk of preeclampsia rises with increasing prepregnancy body mass index. Ann Epidemiol. 2005;15(7):475-482. [PubMed: 16029839]

10. Ruhstaller KE, Bastek JA, Thomas A, McElrath TF, Parry SI, Durnwald CP. The effect of early excessive weight gain on the development of hypertension in pregnancy. Am J Perinatol. 2016;33(12):1205-1210. [PubMed: 27490769]

11. Hernandez-Diaz S, Toh S, Cnattingius S. Risk of pre-eclampsia in first and subsequent pregnancies: prospective cohort study. BMJ. 2009;338:b2255. [PubMed: 19541696]

12. Lynes C, McLain AC, Yeung EH, Albert P, Liu J, Boghossian NS. Interpregnancy weight change and adverse maternal outcomes: a retrospective cohort study. Ann Epidemiol. 2017;27(10):632637 e635. [PubMed: 29033119]

13. McBain RD, Dekker GA, Clifton VL, Mol BW, Grzeskowiak LE. Impact of inter-pregnancy BMI change on perinatal outcomes: a retrospective cohort study. Eur J Obstet Gynecol Reprod Biol. 2016;205:98-104. [PubMed: 27567535]

14. American College of Obstetricians and Gynecologists, Task Force on Hypertension in P. Hypertension in pregnancy. Report of the American College of Obstetricians and Gynecologists' Task Force on Hypertension in Pregnancy. Obstet Gynecol. 2013;122(5):1122-1131. [PubMed: 24150027]

15. Jain AP, Gavard JA, Rice JJ, Catanzaro RB, Artal R, Hopkins SA. The impact of interpregnancy weight change on birthweight in obese women. Am J Obstet Gynecol. 2013;208(3):205 e201-207. [PubMed: 23246318]

16. Linden A Combining propensity score-based stratification and weighting to improve causal inference in the evaluation of health care interventions. J Eval Clin Pract. 2014;20(6):1065-1071. [PubMed: 25266868]

17. Getahun D, Ananth CV, Oyelese Y, Chavez MR, Kirby RS, Smulian JC. Primary preeclampsia in the second pregnancy: effects of changes in prepregnancy body mass index between pregnancies. Obstet Gynecol. 2007;110(6):1319-1325. [PubMed: 18055727]

18. Conde-Agudelo A, Belizan JM. Maternal morbidity and mortality associated with interpregnancy interval: cross sectional study. BMJ. 2000;321(7271):1255-1259. [PubMed: 11082085]

19. Conde-Agudelo A, Rosas-Bermudez A, Kafury-Goeta AC. Effects of birth spacing on maternal health: a systematic review. Am J Obstet Gynecol. 2007;196(4):297-308. [PubMed: 17403398]

20. Basso O, Christensen K, Olsen J. Higher risk of pre-eclampsia after change of partner. An effect of longer interpregnancy intervals? Epidemiology. 2001;12(6):624-629. [PubMed: 11679788]

21. Conde-Agudelo AR-BA, Kafury-Goeta AC. Birth spacing and risk of adverse perinatal outcomes, a meta-analysis. JAMA. 2006;295:1809-1823. [PubMed: 16622143] 


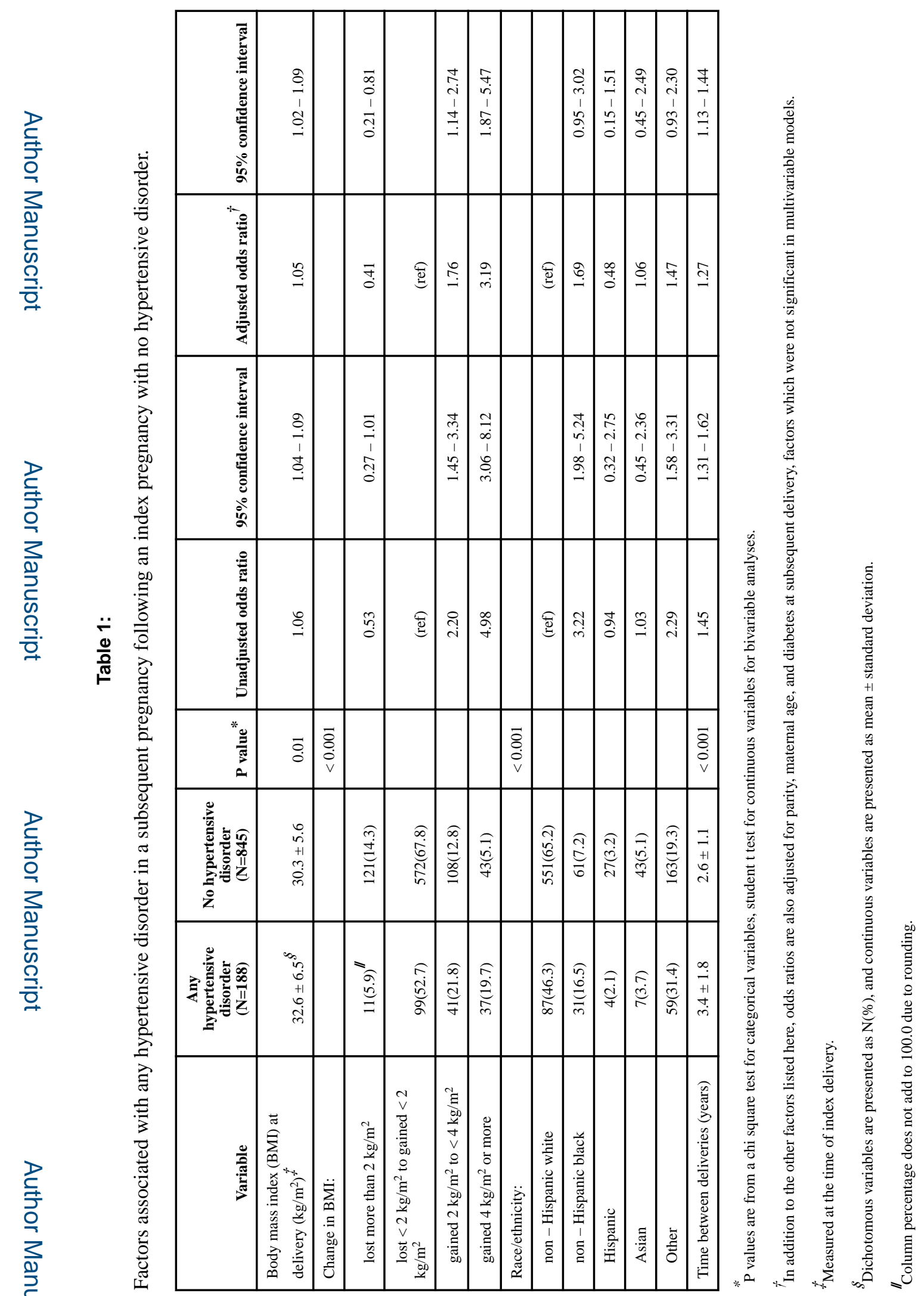

Obstet Gynecol. Author manuscript; available in PMC 2019 October 01. 


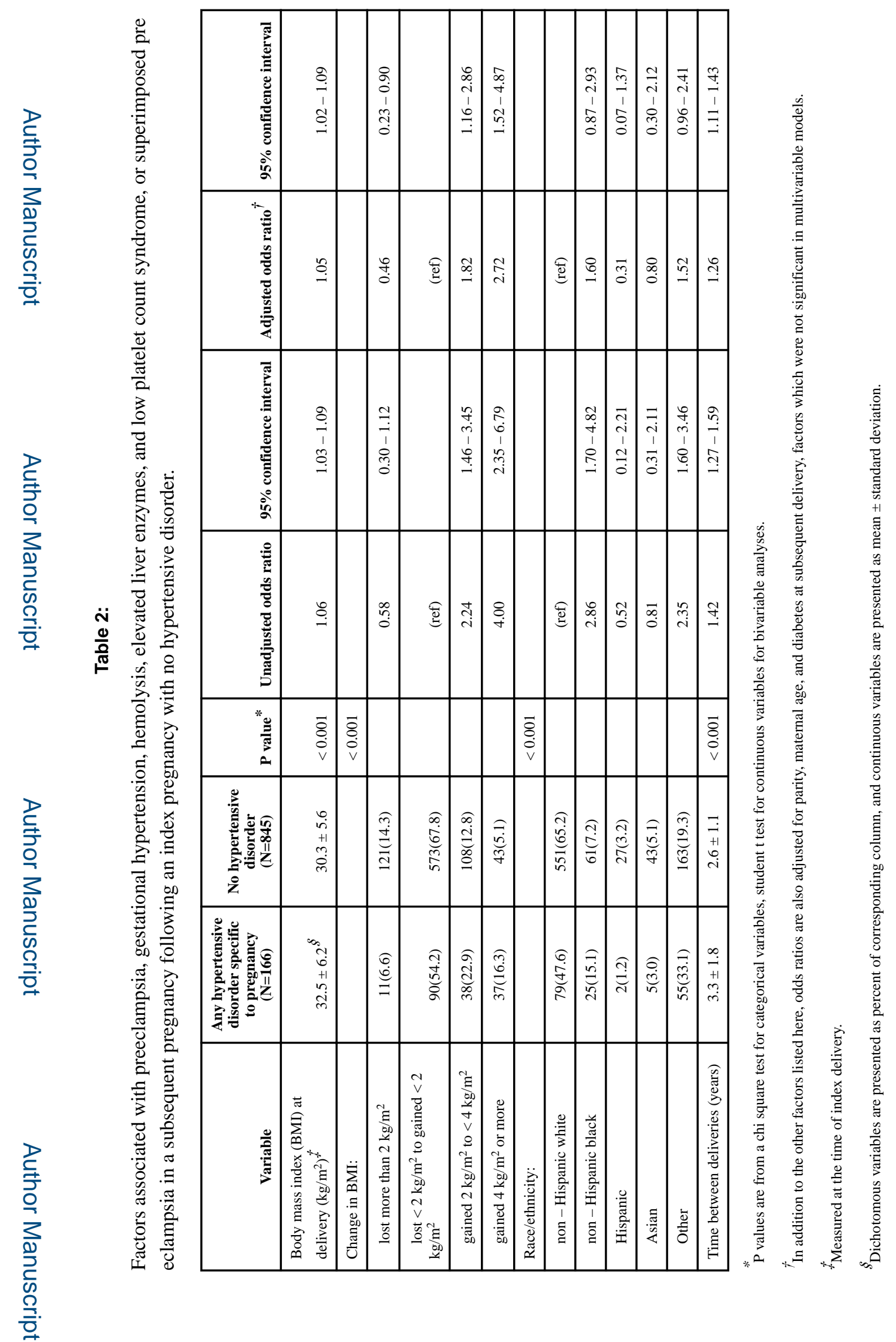

Obstet Gynecol. Author manuscript; available in PMC 2019 October 01. 
Table 3:

Associations of patient characteristics with weight change between deliveries

\begin{tabular}{|c|c|c|c|c|c|}
\hline Variable & $\begin{array}{l}\text { Lost more than } 2 \\
\mathrm{~kg} / \mathrm{m}^{2}(\mathrm{~N}=132)\end{array}$ & $\begin{array}{c}\text { Lost } 2 \mathrm{~kg} / \mathrm{m}^{2} \text { to } \\
\text { gained }<2 \mathrm{~kg} / \mathrm{m}^{2} \\
(\mathrm{~N}=672)\end{array}$ & $\begin{array}{c}\text { Gained } 2 \mathrm{~kg} / \mathrm{m}^{2} \text { to } \\
4 \mathrm{~kg} / \mathrm{m}^{2}(\mathrm{~N}=149)\end{array}$ & $\begin{array}{l}\text { Gained } 4 \text { kg/m } \mathbf{m}^{2} \\
\text { or more }(\mathrm{N}=80)\end{array}$ & $\underline{\text { Pvalue }}^{*}$ \\
\hline \multicolumn{6}{|l|}{ Body mass index: } \\
\hline index delivery & $33.7 \pm 6.2^{\dagger}$ & $30.0 \pm 5.6$ & $30.7 \pm 4.9$ & $32.2 \pm 7.2$ & $<0.001$ \\
\hline subsequent delivery & $29.7 \pm 5.7$ & $30.0 \pm 5.8$ & $33.5 \pm 5.0$ & $39.4 \pm 7.8$ & $<0.001$ \\
\hline Race/ethnicity: & & & & & $<0.001$ \\
\hline white non - Hispanic & $79(59.9)$ & $450(67.0)$ & $75(50.3)$ & $34(42.5)$ & \\
\hline black non - Hispanic & $11(8.3)$ & $43(6.4)$ & $18(12.1)$ & $20(25.0)$ & \\
\hline Hispanic & $5(3.8)$ & $18(2.7)$ & $4(2.7)$ & $4(5.0)$ & \\
\hline Asian & $7(5.3)$ & $37(5.5)$ & $5(3.4)$ & $1(1.3)$ & \\
\hline Other & $30(22.7)$ & $124(18.5)$ & $47(31.5)$ & $21(26.3)$ & \\
\hline Maternal age at delivery (years) ${ }^{t}$ & $33.8 \pm 4.6$ & $33.8 \pm 4.6$ & $33.6 \pm 5.2$ & $32.6 \pm 5.3$ & 0.17 \\
\hline Parity: $:^{t^{t}}$ & & & & & 0.009 \\
\hline one & $106(80.3)$ & $548(81.6)$ & $113(75.8)$ & $53(66.3)$ & \\
\hline two or more & $26(19.7)$ & $124(18.5)$ & $36(24.2)$ & $27(33.8)$ & \\
\hline Time between deliveries (years) & $2.6 \pm 1.0$ & $2.5 \pm 1.2$ & $3.1 \pm 1.5$ & $3.7 \pm 2.0$ & $<0.001$ \\
\hline Diabetes ${ }^{*}$ & $9(6.8)$ & $41(6.1)$ & $10(6.7)$ & $9(11.3)$ & 0.39 \\
\hline
\end{tabular}

P values are from a chi square test for categorical variables, one way ANOVA for continuous variables for bivariable analyses.

${ }^{\dagger}$ Dichotomous variables are presented asN $(\%)$, and continuous variables are presented as mean \pm standard deviation.

Measured at the time of subsequent delivery. 
Table 4:

Factors associated with hypertensive disorders in a subsequent pregnancy following an index pregnancy with no hypertensive disorder, following marginal mean weighting through stratification.

\begin{tabular}{|c|c|c|c|c|}
\hline & \multicolumn{2}{|c|}{ Any hypertensive disorder } & \multicolumn{2}{c|}{ Hypertensive disorder specific to pregnancy } \\
\hline Variable & Adjusted odds ratio $^{*}$ & 95\% confidence interval & Adjusted odds ratio $^{*}$ & 95\% confidence interval \\
\hline Change in BMI: & & & & \\
\hline lost more than $2 \mathrm{~kg} / \mathrm{m}^{2}$ & 0.46 & $0.23-0.91$ & 0.54 & $0.28-1.07$ \\
\hline $\begin{array}{c}\text { lost }<2 \mathrm{~kg} / \mathrm{m}^{2} \text { to gained }<2 \\
\mathrm{~kg} / \mathrm{m}^{2}\end{array}$ & $(\mathrm{ref})$ & & & \\
\hline gained $2 \mathrm{~kg} / \mathrm{m}^{2}$ to $<4 \mathrm{~kg} / \mathrm{m}^{2}$ & 1.70 & $1.10-2.65$ & 1.88 & $1.17-3.00$ \\
\hline gained $4 \mathrm{~kg} / \mathrm{m}^{2}$ or more & 3.61 & $2.04-6.38$ & 2.62 & $1.43-4.81$ \\
\hline
\end{tabular}

* Odds ratios reflect reweighting and stratification of the dataset to account for observed characteristics across treatment groups. 